\title{
A PRODUÇÃO CIENTÍFICA E A ÉTICA EM PESQUISA
}

\section{SCIENTIFIC PAPERS OUTCOME AND RESEARCH ETHICS}

\section{Luiz Carlos Duarte de Miranda, ACBC-RJ}

As pesquisas científicas que envolvem a participação de indivíduos em seus protocolos, não raro se defrontam com dilemas de ordem ética, cuja solução requer uma reflexão cuidadosa, apoiada por preceitos já estabelecidos por resoluções e bom senso por parte dos pesquisadores.

O conhecimento mínimo em relação aos preceitos das Resoluções em vigor, não só dinamiza o processo de aprovação junto aos comitês de ética, bem como fortalece o conteúdo humano do protocolo que se pretende desenvolver.

As resoluções vêm sendo aprimoradas ao longo dos tempos, recebendo novos conceitos em função das necessidades de cada época, fazendo-nos perceber que se trata de um processo dinâmico, passível de reformulações e aquisições. Conhecendo um pouco de sua evolução, entendemos melhor o âmago de sua estrutura, que, na verdade, é a essência da preservação do bem estar e da dignidade da nossa espécie.

O primeiro conjunto de diretrizes para pesquisa em humanos, aceito pela comunidade científica, data de 1833 , publicado por William Beaumont, onde se destacaram: um texto onde o sujeito da pesquisa manifestaria o seu consentimento voluntário, ainda, uma adequação metodológica do projeto de pesquisa e a condição imutável de liberdade para sair da pesquisa ${ }^{1}$.

A primeira condenação judicial por realizar pesquisa "sem autorização antecipada", data de 1880, quando a corte da cidade de Bergen, na Noruega, condenou o doutor Gerhardt A. Hansen. Naquela ocasião o Dr. Hansen inoculou um líquido de uma ferida nos olhos de uma anciã, querendo comprovar a fácil transmissão daquela moléstia (lepra), mas não colheu o seu consentimento prévio, e foi condenado à prisão ${ }^{2}$.

Em 1947, em conseqüência das atrocidades cometidas na Segunda Grande Guerra, foi elaborada a Declaração de Nuremberg, cujos dez princípios passaram a determinar as orientações éticas para experimentos com humanos. Nela, além de considerar o consentimento voluntário do sujeito da pesquisa como absolutamente essencial, condicionou o estudo a um desenho cientificamente sólido (com experimentos prévios em animais), e a necessidade de que fosse conduzido por indivíduos "qualificados", com a expressa preocupação de "não fazer mal", e declarar os riscos e benefícios esperados para aquela experiência ${ }^{2}$.

Em 1964, surge a Declaração de Helsinque estabelecendo duas novas exigências: 1) Formular um Protocolo da pesquisa e 2) Submetê-lo a um Comitê de Ética. De 1964 até o ano 2000 (Edimburgo) esta Declaração já foi modificada por 5 vezes.

A Regulamentação Brasileira de Ética em Pesquisa em Seres Humanos data de 1996, quando em 10 de outubro o então ministro de Saúde, Prof. Dr. Adib Jatene, assinou a Resolução 196/96, que veio para atualizar as Resoluções 1246/88 do Conselho Federal de Medicina e a 01/88 do Conselho Nacional de Saúde. A partir daquela data, novas resoluções foram incluídas, destacando-se a 240/97 estabelecendo a obrigatoriedade de um representante dos USUÁRIOS nos Comitês de Ética em Pesquisa (CEP); ainda: 251/97 estabelecendo regras para experiências com novos fármacos; a 292/99 organizando as pesquisas que têm coordenação multicêntrica e internacional; a 303/00 estipulando os conceitos válidos para estudos que envolvem a reprodução humana; a 304/00 para com as pesquisas que utilizam povos indígenas e a 340 / 04 para os estudos incluindo genética humana ${ }^{1,3}$.

A resolução 196/96 tem um texto muito prático e abrangente, estabelece a composição dos comitês (multidisciplinaridade; atribuições; organização; mandato, etc.), cria a Comissão Nacional de Ética em Pesquisa - CONEP, que regulamenta no âmbito nacional as pesquisas de temas como SIDA, genética e reprodução humana, e novos fármacos.

Em 2001 estabeleceu-se o Sistema de Informação Nacional sobre Ética em Pesquisa (SISNEP) onde estão cadastrados todos os projetos que deram entrada em um CEP já oficializado. Esses projetos podem ser localizados em: www.saude.gov.br/sisnep/pesquisador.

Os CEP estão preparados para orientar na confecção do projeto de pesquisa e na elaboração de um termo de Consentimento Livre e Esclarecido (TCLE) que estejam de acordo com a Resolução 196/96.

$\mathrm{O}$ avanço da produção científica brasileira catalogado pela base de dados da ISI (Institute for Scientific Information ) revela um crescimento expressivo. Na década de 60 foram publicados em média 52 artigos/ano; em 1970 foram 64 artigos (0,019\% da produção mundial). Em 2001 a produção brasileira catalogada naquela base de dados foi de 10.555 artigos completos, 76 vezes maior do que a produção média mundial. A partir de então, ocupamos posição destacada no ranking da produção científica mundial, como $18^{\circ}$ da lista (os EUA em $1^{\circ}$ respondem por $34 \%$ da produção mundial.

Neste contexto inclui-se o desempenho científico das áreas médica e biomédica. No período entre 1997 e 2001 a pesquisa em medicina produziu 7.365 artigos, $23^{\circ}$ lugar no

Professor Adjunto do Departamento de Cirurgia da Faculdade de Medicina- UFRJ.

Recebido em 15/10/2006

Aceito para publicação em 20/11/2006

Conflito de interesse: nenhum

Fonte de financiamento: nenhum 
mundo e a $3^{\mathrm{a}}$ na produção interna, representando $16 \%$ do total dos artigos indexados na base ISI, com um índice qualitativo de 52,8\% de artigos citados e 2,8 de índice de impacto na área médica; se incluídas as sub áreas (biomédicas) o índice de impacto sobe para 3,3 mas, mesmo assim, ainda muito abaixo dos parâmetros mundiais da área $(8,0)$.

A capacidade instalada no nosso país corresponde, segundo o censo de 2002 da Coordenação de Aperfeiçoamento de Pessoal de Nível Superior (CAPES), a aproximadamente 15 mil grupos de pesquisa, 68 mil pesquisadores, 43 mil com Doutorado, cerca de 1800 programas de Pós Graduação com 30 mil docentes-Doutores, com 100 mil alunos matriculados. (www.capes.gov.br)

Estes dados apontam para um ritmo de crescimento na capacidade e qualificação de novos pesquisadores, mas ainda são insuficientes para a competição já estabelecida rumo ao desenvolvimento científico e tecnológico, estando muito aquém dos índices necessários para uma contribuição no desenvolvimento social e econômico.

A capacitação de Comitês de Ética em Pesquisa deve ser encarada como instrumento fundamental para o desenvolvimento/competição na área biomédica do nosso país. Assim, cabe às instituições de pesquisa promover a evolução dos comitês, absolutamente fundamentais na estratégia para o avanço científico e tecnológico, e também enriquecer os programas de Pós Graduação com conhecimentos relativos aos conceitos estabelecidos para a pesquisa ética.

Após 6 anos de experiência no CEP - Hospital Universitário Clementino Fraga Filho (HUCFF) - UFRJ, dos quais 3 como coordenador do Comitê, podemos afirmar que é uma atividade importantíssima para os que têm o perfil voltado para o ensino e a pesquisa. Como membro do Comitê senti as dificuldades que enfrentam os pesquisadores frente à confecção dos protocolos, para adequá-los às Resoluções, a fim de que sejam elaborados os seus projetos que culminarão com a defesa de tese e a publicação em periódicos de valor.

Não raras são as ocasiões em que o comitê sugere alterações na metodização, tornando-a viável, capaz de produzir resultados com consistência.

$\mathrm{Na}$ responsabilidade de coordenador procuramos uniformizar, entre os membros do comitê, os critérios para análise dos protocolos porque a profissão ou área de atuação do autor ,na maioria das vezes, não coincide com o tema do trabalho enviado. A elaboração de um roteiro baseado nas Resoluções torna as análises mais uniformes. Assim, um projeto de pesquisa do Programa de Pós-Graduação em Dermatologia, por exemplo, poderá ser analisado por um membro da Enfermagem, da Nutrição, por um Sociólogo ou por um Teólogo, que conhecendo a resolução 196/96 e seguindo os critérios para análise do protocolo e do Termo de Consentimento Livre e Esclarecido (TCLE), emitirá um parecer que será discutido na reunião ordinária.

Um capítulo que merece maior consideração, sem dúvida, é o que se refere ao TCLE. Este, na verdade, se constitui um acordo entre o pesquisador e o sujeito da pesquisa, o voluntário. Neste acordo firmado estarão incluídas todas as cláusulas de proteção mútua, tornando-o um elemento de "defesa" bilateral (pesquisador e voluntário).

Portanto, o TCLE deverá ter uma linguagem absolutamente acessível ao leigo, não comportando expressões cuja complexidade possa criar dúvida; assim, por exemplo, dizer que "está prevista uma venóclise", deverá ser substituído por "uma injeção na veia do braço que vai aspirar o sangue, no volume de mais ou menos uma colher de sopa". Parece primário, mas é assim que deve ser feito.

Ainda, o TCLE deverá ter uma boa introdução, explicando o motivo do trabalho, o motivo do convite àquela pessoa, o porquê dela estar sendo convidada e, assim sendo, poderá ou não aceitar e depois desistir, sem que isso a prejudique em relação ao tratamento que faz ou ao que pretenda fazer. Não há como não falar dos riscos e benefícios, de forma ampla e clara. É necessário que sejam descritos em detalhes todos os procedimentos previstos e assegurar um meio de contato (telefone) em caso de dúvida. Enfim, ainda vários outros elementos importantes irão compor este verdadeiro "contrato de participação" e é absolutamente fundamental que o trabalho só tenha início após a aprovação pelo CEP, e assim, só incluir pessoas que assinaram o TCLE.

No CEP-HUCFF- UFRJ passam em média 280 a 300 projetos novos por ano, vários deles oriundos de Pós-Graduações $(60 \%)$ e de outros centros de pesquisa, por vezes internacionais, dando oportunidade para o intercâmbio de conhecimentos e novas tecnologias. Estes, por sua vez, irão gerar futuros documentos (relatórios, relatos de eventos adversos, emendas, extensões) que estarão sendo monitorizados e analisados pelo CEP.

Portanto, a qualificação de CEP, se constitui num objetivo estratégico nas Unidades de Ensino e Pesquisa, e o coração de cada um deles está na equipe de membros, que lhe conferem alma. O gabarito do CEP estará diretamente relacionado à eficiência de seus membros, cujo caráter de voluntariado e multidisciplinaridade lhes confere autonomia absoluta para desempenhar suas funções.

\section{REFERÊNCIAS}

1. BRASIL. Ministério da Saúde. Capacitação para Comitês de Ética em Pesquisa. Comunicação e Educação em Saúde, 2006. Série F, vol. 1 e 2 .

2. França, G. Comentários ao Código de Ética Médica. $3^{\mathrm{a}}$ ed. Rio de Janeiro: Guanabara Koogan; 2000. p. 200-4 (Declaração de Helsinque II) p. 223 (Declaração de Nuremberg).

3. Beecher, H. Ethics and Clinical Research. N Engl J Med. 1966; 274(24): 1354-1360.

Como citar este artigo:

Miranda LCD. A produção científica e a ética em pesquisa. Rev Col Bras Cir. [periódico na Internet]. 2006 Nov-Dez;33(6). Disponível em URL: www.scielo.br/rcbc

Endereço para correspondência: Luiz Carlos Duarte de Miranda Rua Visconde de Pirajá, 55/ / 2111 22410-003 - Rio de Janeiro - RJ E-mail: lmiranda@hucff.ufrj.br 